\title{
Effectiveness of Self Instructional Module on Central Venous Catheter Care among ICU Nurses
}

\author{
K. J. Pushpakala ${ }^{1}$, Achu Ravinath ${ }^{2}$ \\ ${ }^{1}$ Associate Professor - Cardio Thoracic Nursing Department,Chettinad Hospital And Research Institute \\ ${ }^{2}$ Staff Nurse-Cardio thoracic ICU, Chettinad Super Speciality Hospital, Tamilnadu, India.
}

\begin{abstract}
Central venous catheters are often used as mandatory devices when caring critically ill patients. Catheter-related blood stream infections are associated with significantly increased morbidity, mortality, and expenditures. Despite technological advances, an estimated 250,000 catheter related blood stream infections occur annually. Advanced practice nurses possess the power to influence catheter-related line infections in their critical care units. Understanding current recommendations for catheter material selection, site selection, site preparation, and site care can affect rates of catheter-related bloodstream infections ${ }^{3}$.

Central venous catheterization can be lifesaving but is associated with complication rates of approximately $15 \% .{ }^{10} \mathrm{~A}$ study done at Escort Heart Centre, New Delhi shows that mortality due to central venous catheter related blood stream infection was $22.9 \%$ as compared with $0.2 \%$ in non central venous catheter related blood stream infection ${ }^{11}$. Many Studies shows that education of nurses and proper care of central venous catheters can reduces infection rates by 41 to $66 \%$ in adult ICUs. Hence, this study was aimed to determine effectiveness of self instructional module on central venous catheter care.

The aim of the study was to impart the current recommendation regarding nursing care of patient with central venous catheter among staff nurses working in ICU. An Evaluative approach was used for the present study. Using purposive sampling technique 50 samples were selected from Chettinad Hospital and Research institute, Tamil Nadu, India. The tool used was self administered questionnaire. The collected data was analyzed using descriptive and inferential statistics. The findings of the study revealed a significantly increase in the staff nurses knowledge score after administration of self instructional module. The mean pre test score was $9.80 \%$ and the mean post test score was $16.58 \%$ and the difference between pre test and post test knowledge score was $6.78 \%$ Based on the objectives of the study the findings of the level of knowledge score on staff nurses shows that they were able to gain adequate knowledge. The study shows that the staff nurses in post test were having average of moderately $30 \%$ knowledge and adequate $70 \%$ of knowledge regarding nursing care of patients with central venous catheter. Self instructional module is effective in increasing the knowledge regarding nursing care of patients with Central venous catheter among staff nurses.
\end{abstract}

Key Words: Knowledge, Module on Central venous catheter care, staff nurses, effectiveness

\section{Introduction}

Nursing staff development programme helps to shape the future of the nursing profession and nursing service. Nursing Staff development is the key to quality nursing care that helps to facilitate the competence of nurses in practice. It began with Florence Nightingale's effort in the Crimean war, when she worked with nurses to improve the care they were providing. Part of her responsibility as a supervisor or director of nursing care, she was to ensure that the "nurses" provided care based on standards Nurses play a key role with critically ill patients who require continuous assessment of their cardiovascular system to diagnose and manage their complex medical conditions. Central venous catheters are often used as a mandatory device when caring critically ill patients. A study was conducted to determine intensive care unit (ICU) nurses' knowledge of evidence-based guidelines for preventing central venous catheter (CVC) related infection. The study results proved that nurse's knowledge about care of central venous catheters was not adequate. ${ }^{1}$ Improper management of central venous catheter can give rise to various complications like line embolism, thrombosis, infection/sepsis, ischemia of involved limbs, cardiac perforation, pneumothorax, accidental puncture of an artery leading to bleeding, catheter displacement etc.

Today nursing has changed from traditional intuitive nursing to modern cyber space nursing. Technological advances demand more qualified and specially trained nurses, particularly in critical areas, emergency areas and in medical surgical units in the tertiary care hospitals. Nurse's role is to apply that technological knowledge in an efficient and cost effective manner. It is essential for nursing and medical personnel who are responsible for effective conduct of central venous catheter care, to have clear picture of its techniques, peculiarities, and above all its inherent dangers. So ,the investigator intended to determine the existing knowledge of staff nurses regarding nursing care of patient with central venous catheter, with a view to develop the self instructional module on care of patient with central venous catheter and to test its effectiveness. 


\section{Objectives of the Study}

- To assess the pretest and post test knowledge regarding nursing care of patients with Central Venous Catheter among staff nurses.

- To evaluate the effectiveness of Self Instructional Module on nursing care of patients with Central Venous Catheter.

- To find out the association between the post test level of knowledge on nursing care of patients with Central Venous Catheter with selected demographic variables.

\section{Materials And Methods}

The research design in this study was pre experimental study. The sample was 50 staff nurses working in intensive critical care units, coronary intensive care unit and cardio vascular intensive care unit who fulfill the sampling criteria. The questionnaire consists of 2 parts. Part 1 consist of selected demographic variables like age,gender,educational qualification, year of experience,year of experience in ICU,whether attended any continuous Nursing education programme(CNE) on care of patient with central venous catheter.Part 2 consists of Knowledge Questionnaire on nursing care of patient with Central Venous Catheter. Staff nurses who working in ICU were selected through purposive sampling technique. The pretest knowledge level was assessed by structured questionairre.Then Self Instructional Module was given for staff nurses after pretest.After seven days the post test knowledge was assessed with the same tool.

The study was conducted during the period of May2013-june 2013 in the intensive critical care units of selected tertiary hospital, Chennai.

\section{Statistical Analysis}

The data of the present study were planned to be analyzed based on specific objectives and hypothesis. The data obtained from 50 staffs would be analyzed by using descriptive and inferential statistics as follows:

- Descriptive statistics method such as frequencies and percentage was used to assess the demographic variables and level of knowledge among staff nurses.

- The comparison between the pre test and post test level of knowledge evaluated by paired ' $t$ ' test.

- The association between the level of knowledge and selected demographic variables evaluated by Inferential statistical method ie Chi square

Table: 1 Frequency And Percentage Distribution Of Knowledge On Care Of Patient With Central Venous Catheter Among Staff Nurses

\begin{tabular}{|c|c|c|c|c|c|}
\hline \multirow{2}{*}{ S.NO } & \multirow{2}{*}{ Level Of Knowledge } & \multicolumn{2}{|c|}{ Pretest } & \multicolumn{2}{c|}{ Post Test } \\
\cline { 3 - 5 } & & Frequency & Percentage & 35 & 70 \\
\hline 1. & Adequate Knowledge & 0 & 0 & 15 & 32 \\
\hline 2. & Moderately Adequate & 26 & 48 & 0 & 0 \\
\hline 3. & Inadequate & 24 & 50 & 0 \\
\hline
\end{tabular}




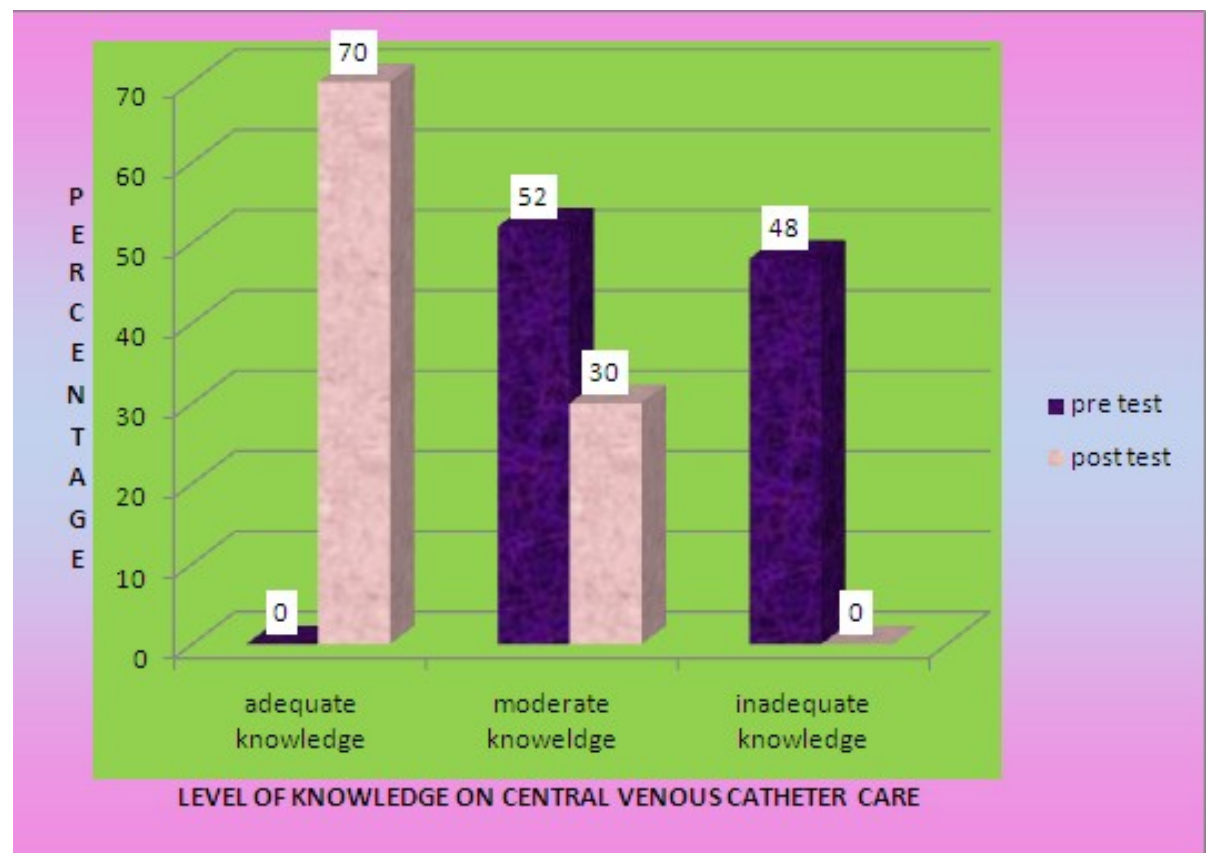

\section{Results}

Level of knowledge of fifty staff nurses regarding care of patient with central venous catheter was assessed by structured questionnaire and analyzed using descriptive statistics that indicates the mean pre test knowledge score with mean $(\mathrm{X} 1=9.80)$ and standard deviation $(2.32)$. The study result shows a tremendous mean difference (6.78) in the knowledge of subjects regarding selected aspects after the administration of self instructional module on nursing care of patient with central venous catheter. Data depicts that the mean post test knowledge mean score $(\mathrm{X} 1=16.58)$ was higher than the mean pre test knowledge score. The computed $\mathrm{t}$ value shows that there was a significant difference between the two mean knowledge score. The study shows a tremendous difference in the knowledge of on nursing care of patient with central venous catheter among staff nurses after the administration of self instructional module. The accepted $t$ value is greater than the table value $(\mathrm{t}=2.32 ; \mathrm{p}<0.05)$.

\section{Conclusion}

The result from this study reveals that the knowledge on nursing care of patient with central venous catheter among staff nurses was inadequate and moderately adequate. This has to be taken into consideration. There may be many reasons for staff nurses inadequacy, which can be improved upon. Self instructional module is one of the effective methods in increasing and updating the knowledge regarding nursing care of patient with central venous catheter among staff nurses. The findings of the study revealed that there was a significantly increased in the post test knowledge scores after administration of self instructional module.

\section{References}

[1]. Rosza Konczne Reti., Erika Vass and Katalin Darvas. (2008). "Intensive care unit (ICU) nurses Knowledge of evidence-based guidelines for preventing central venous catheter related Infection". Retrieved from http://www.ajcconline.org/

[2]. Mary Courtney. (2004). Central Venous Catheter Infections. Journal of Advanced Nursing, 18(3), $247-256$.

[3]. M Pawar., Y Mehta.( 2006 ).The incidence, risk factors, outcome, and pathogens of central venous catheter-related bloodstream infections. Journal of Cardiothoracic and Vascular Anesthesia, 18 (3), $304-308$.

[4]. Division of Pediatric Hematology, McMaster University, Canada. (2006). Effect of heparin on thrombus formation and infection associated with use of central venous and pulmonary artery catheters. Critical Care Nurse, 26(2), 137 - 138.

[5]. Robert R. Muder, MD. (2011). Infection Control and Hospital Epidemiology.Brazillian journal of Infectious diseases, 22(3), 134135 .

[6]. Girard R., Comby C., Jacques D. (2010). Alcoholic povidone-iodine or chlorhexidine-based antiseptic for the prevention of central venous catheter-related infections: in-use comparison. Critical care medicine, 77(5), 549-58. 